\title{
Preface: application of operations research to financial markets
}

\author{
loannis Kyriakou ${ }^{1} \cdot$ Athanasios A. Pantelous $^{2}$ - Georgios Sermpinis ${ }^{3}$. \\ Stavros A. Zenios ${ }^{4,5,6}$
}

Published online: 1 October 2019

(c) Springer Science+Business Media, LLC, part of Springer Nature 2019

This special issue of the Annals of Operations Research comprises a selection of papers from worldwide researchers in the field. We encouraged submissions from the 3rd Symposium on Quantitative Finance and Risk Analysis (QFRA) held in June 2017 at the island of Corfu in Greece, although the call for papers was open to all researchers in the field.

A total of 41 submissions were received and, following a thorough peer-review process, we selected 18 papers to include in this special issue. The papers cover a wide range of operations research application in finance constituting a subtle blend of theory, practice, implementation, and empirical studies. In particular, the accepted papers bring de novo contributions to problems relating to asset pricing, estimation, forecasting, portfolio selection and optimization, trading strategies, and financial risks.

We would like to thank all the authors who submitted their valuable papers to this special issue. We extend our gratitude to all the referees for their devotion and time to reading, assessing, and providing high-quality reports for the papers they reviewed that definitely helped the authors enhance their papers and us to make our final decision. Finally, we would like to thank the Editor-in-Chief, Professor Endre Boros, for giving us the

Ioannis Kyriakou

ioannis.kyriakou@city.ac.uk

Athanasios A. Pantelous

athanasios.pantelous@monash.edu

Georgios Sermpinis

georgios.sermpinis@glasgow.ac.uk

Stavros A. Zenios

zenios.stavros@ucy.ac.cy

1 Cass Business School, City, University of London, 106 Bunhill Row, London EC1Y 8TZ, UK

2 Department of Econometrics and Business Statistics, Monash University, Clayton, VIC 3800, Australia

3 Adam Smith Business School, University of Glasgow, Glasgow G12 8QQ, UK

4 Department of Accounting and Finance, University of Cyprus, Nicosia, Cyprus

5 Non-resident Fellow, Bruegel, Brussels, Belgium

6 Wharton Financial Institutions Center, University of Pennsylvania, Philadelphia, USA 
opportunity to guest edit this special issue, as well as the Publication Managers, Katie D’Agosta and Ann Pulido, for their assistance in all editorial matters.

Publisher's Note Springer Nature remains neutral with regard to jurisdictional claims in published maps and institutional affiliations. 